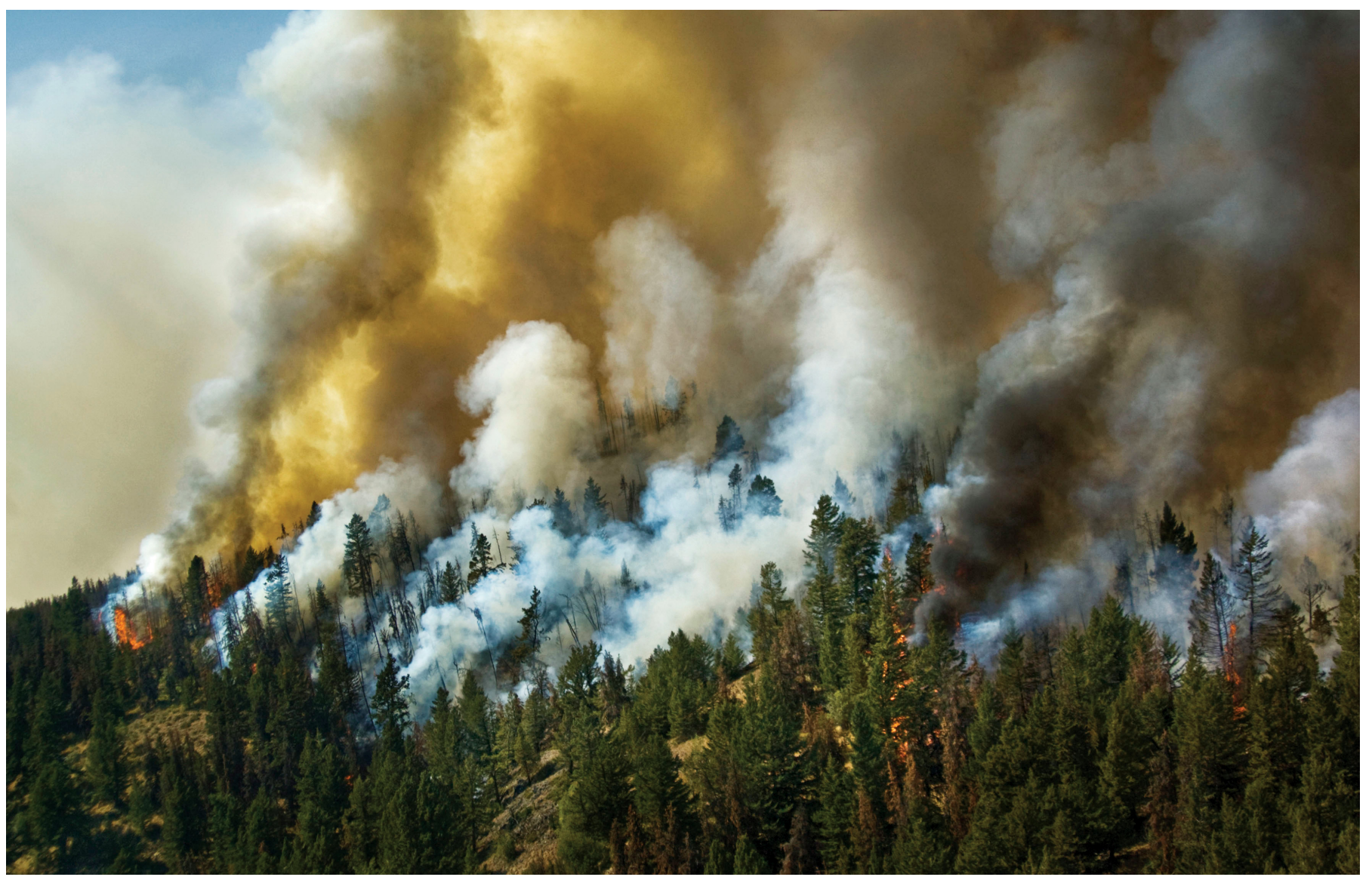

Figure 1 | Wildfires in Canadian boreal forests. Walker and colleagues ${ }^{5}$ analysed the type of carbon lost from organic soils under black spruce in forests of the Northwest Territories of Canada after fires.

\title{
Soils linked to climate change
}

\section{Carbon has been stored in the organic layers of boreal-forest soils for hundreds of years. An analysis reveals that this} carbon might be released into the atmosphere as global warming increases the frequency of wildfires. SEE LETTER P.520

\section{CORNELIA RUMPEL}

$\mathrm{B}$ oreal forests are key players in the global carbon cycle, because they store $30-40 \%$ of terrestrial carbon ${ }^{1}$. They have been considered to be carbon sinks, mainly because they accumulate large amounts of carbon in the form of organic soils ${ }^{2}$. Their net carbon balance is driven by natural wildfires (Fig. 1), which produce large carbon emissions approximately every 70 to 200 years ${ }^{3}$, and which are necessary to maintain the productivity and biodiversity of these forests. But climate change is likely to shorten the period between fires (the fire-return interval) by producing warmer temperatures, more lightning strikes, longer wildfire seasons and drier forest conditions than those seen at present ${ }^{4}$. On page 520, Walker $e t a l .{ }^{5}$ show that the increase in fire frequency might turn boreal forests from carbon sinks into carbon sources.

The cause of this shift is due to the impact of more-frequent fires on legacy carbon - the organic carbon that has escaped earlier fires and has accumulated at the surface of borealforest soils. A boreal forest will act as a carbon sink if a fire removes less soil carbon than the amount that accumulated after the previous fire - or, to put it another way, if the soil carbon removed by a fire is younger than the community of trees affected by the fire.

Walker and co-workers used an original method to investigate the origin and age of soil carbon lost in the 2014 fires in black spruce forests in the Northwest Territories of Canada. They estimated the amount of carbon present before and after the fires in organic soil layers overlying mineral soils at 211 forest sites, as well as the carbon emissions produced from the burning of above- and below-ground organic material at those sites. At 32 of the sites, they also analysed the abundance of radioactive carbon-14 isotopes in the organic soil at multiple depths to work out the age of the carbon affected by the fire. This soil-based approach revealed that legacy carbon was lost in young forests at dry sites, whereas old forests at wet sites still accumulated carbon at their surface.

By specifically investigating the type of carbon lost from soil (legacy and non-legacy carbon), rather than just quantifying total emissions, Walker et al. have greatly improved our mechanistic understanding of how fire 
affects the ability of boreal forests to act as a carbon sink at the landscape scale. Their work also highlights the importance of considering below-ground stores of terrestrial carbon to understand ecosystem responses to climate change.

Walker and colleagues' results suggest that certain boreal forests are about to reach a tipping point in their resilience to fire, beyond which the carbon-storage function of this ecosystem will change. This is a major concern, not only because it will increase the rate at which carbon dioxide is released to the atmosphere, but also because these forests provide multiple benefits. Boreal forests constitute the largest terrestrial biome, with some of the world's largest intact areas of untouched forest, and they harbour unique biodiversity. Moreover, they are sources of timber products and contribute greatly to global air quality and climate regulation. Carbon loss and removal of organic soils by fire will transform this ecosystem, with unknown consequences.

For example, increased fire frequency might alter species composition and biodiversity, and will probably affect soil fertility as a result of carbon removal. Boreal forests could therefore become less productive than they are at present, and more vulnerable to other stresses, such as insect attacks and droughts, which are likely to become more frequent as the climate changes. These effects, in turn, will further decrease the carbon-sink function of boreal forests and adversely affect the economies of countries that rely on timber harvests. Because it is extremely difficult to predict what, when and where changes will happen, these effects present a challenge for forest managers and policymakers ${ }^{6}$.

Walker and co-workers' study demonstrates that there is an intimate link between soils and climate. The authors suggest that the increased frequency of fires in boreal forests is resulting in a positive feedback loop: a higher incidence of fires means that younger forests will be affected, increasing the probability that legacy carbon will be released from soil (assuming that the intensity of the fires does not change). Legacy carbon has been sequestered for hundreds of years; its release would further increase atmospheric $\mathrm{CO}_{2}$ concentrations, thereby accelerating climate change.

The effects of wildfires reported by Walker et al. are specific to organic soils that have accumulated large amounts of organic matter because low temperatures and/or high water tables have protected them from microbial decomposition. Such soils are widespread in boreal regions, but are also found in temperate and tropical climates ${ }^{7}$. These organic soils, which contain more than $20 \%$ carbon, are very different from the relatively carbon-poor mineral soils that underlie most temperate and tropical forests and grasslands.

Disturbances such as increasing temperatures and fire will trigger much bigger carbon losses from boreal organic soils than from mineral soils in temperate and tropical regions ${ }^{7}$. This is because a large proportion of the organic matter in mineral soils is protected from microbial decomposition by its interaction with soil minerals, preserving it as temperatures increase, and because mineral soils have low heat conductivity, which usually protects organic matter from fire. However, if the organic soil layers of boreal forests are reduced in the future, more attention will need to be paid to the organic carbon in the underlying mineral soils. Mineral soils under boreal forests store substantial amounts of carbon ${ }^{6}$, but Walker et al. did not take this into account in their analysis.

Because of the contrasting processes that protect carbon in organic and mineral soils, different strategies are needed to manage their carbon-sink function. For organic soils, it will be necessary to maintain low temperatures, high moisture levels and low fire-return intervals ${ }^{4,7}$. This will require immediate, aggressive reductions in greenhouse-gas emissions from all sectors of society to minimize further increases in atmospheric $\mathrm{CO}_{2}$ concentrations and climate change. To improve the carbonsink function of mineral soils, sustainable management practices for forestry and agriculture must be adopted. In both cases, awareness of the benefits of soil carbon must be raised, and collaboration is needed at all levels from everyone who uses soils, and from those whose activities might damage soils.

Cornelia Rumpel is at CNRS, Institute of

Ecology and Environmental Sciences, Campus AgroParisTech, Thiverval-Grignon F-78850,

France.

e-mail:cornelia.rumpel@inra.fr

1. Kasischke, E. S., Christensen, N. L. Jr \& Stocks, B. J. Ecol. Appl. 5, 437-451 (1995).

2. De Groot, W. J., Flanningan, M. D. \& Cantin, A. S. For. Ecol. Mgmt 294, 35-44 (2013).

3. Bergeron, Y., Flannigan, M., Gauthier, S., Leduc, A. \& Lefort, P. AMBIO 33, 356-360 (2004).

4. Goodale, C. L. et al. Ecol. Appl. 12, 891-899 (2002).

5. Walker, X. J. et al. Nature 572, 520-523 (2019).

6. Price, D. T. et al. Environ. Rev. 21, 322-365 (2013).

7. Leifeld, J. \& Menichetti, L. Nature Commun. 9, 1071 (2018).

\section{IMMUNOLOGY}

\section{Regulators to the rescue}

\section{A type of immune cell called a CD8 T cell, which usually kills disease-causing agents, has been found instead to suppress self-reactive immune cells, thereby offering protection against an autoimmune disease in mice. SEE ARTICLE P.481}

\section{HYE-JUNG KIM \& HARVEY CANTOR}

$\mathrm{T}$ The immune system has evolved complex mechanisms that allow rapid and destructive responses to microbial intruders while sparing the host's own tissues. Regulation of this delicate balance depends mainly on the immune system's two major types of $\mathrm{T}$ cell, which are distinguished by the protein - either CD4 or CD8 - that is expressed on their surface. They are called CD4 T cells and CD8 T cells, respectively. The task of CD8 T cells has generally been assumed to be to kill cells infected with microbial invaders and to destroy foreign or abnormal cells. However, Saligrama et al. ${ }^{1}$ report another role on page 481: CD8 T cells can inhibit self-reactive CD4 T cells and quell autoimmune disease in a mouse model of multiple sclerosis.

In previous work ${ }^{2}$, researchers from the present group showed that, if people with coeliac disease were exposed to gluten proteins (a major type of trigger, called an allergen, in this autoimmune disorder), it activated not only CD4 T cells that could specifically recognize gluten, as expected, but also a subset of CD8 T cells. Exactly what the latter were doing, however, was unclear. Saligrama and colleagues now report their investigation into whether a similarly coordinated T-cell response might be detected in experimental autoimmune encephalomyelitis (EAE), which is a mouse model of multiple sclerosis. This autoimmune model can be induced by injecting the protein myelin oligodendrocyte glycoprotein (MOG), a component of the fatty coating of nerve cells called myelin, into mice. The authors identified populations of both CD4 and CD8 $\mathrm{T}$ cells (among other immune cells) that proliferated vigorously after immunization with MOG, generating clones of cells (Fig. 1a).

For each of these mobilized populations, Saligrama et al. identified the T-cell antigen receptors (TCRs, the proteins on T cells that recognize foreign or self peptide fragments known as antigens), and attempted to identify antigens that the TCRs could recognize. Such recognition causes T-cell activation and proliferation. The authors found that the CD4 T cells in question recognized MOG-derived peptide fragments and so were primed to specifically attack myelin-coated nerve cells and cause disease. But the CD8 T-cell clones did not recognize MOG, and none of about 350 myelin-derived peptides tested could activate their TCRs. So how were these cells being activated?

To find out, the authors generated a library of roughly $10^{8}$ different peptides, each embedded 